\title{
Thermal Management and System Optimization of Heat Transfer Performance Using Nanotechnology: A Hybrid Thermal and Environmental Application
}

\author{
Prof. Ziad Sigher \\ Department of Mechanical and Industrial Engineering \\ Ryerson University, Toronto, Canada
}

\begin{abstract}
Thermal transport mechanism is a key element in thermofluid optimization fields. The heat transfer fluid plays an important role in heat absorption for various industrial applications such as in solar collectors, power plant condenser, electronics cooling, etc. The most common and widely used heat transfer fluid is ethylene glycol, water and oil base cooling fluid. The major problem with these fluids is; it has a low thermal conductivity value which produces poor performance in heat removal and cooling applications. It also has limited thermophysical property. As such, a new approach is in need to be figured to maximize the heat absorption. The development of thermal transport fluid should be primarily focusing on having high thermal conductivity properties as it is vital to fulfilling the industrial requirement for massive heat transfer for cooling and heating purposes. A mixture of nanofluid and Microencapsulated Phase Change Material is proposed to be used for heat enhancement and heat storage. Bulk phase change material will also be presented and discussed.
\end{abstract}

